\title{
Microeconomic Uncertainty and Macroeconomic Indeterminacy ${ }^{1}$
}

\author{
Jean-François Fagnart \\ THEMA, Université de Cergy-Pontoise \\ and
}

Henri R. Sneessens

IRES, Université catholique de Louvain, and Université catholique de Lille

April 2001

\footnotetext{
${ }^{1}$ We are most grateful to Jorge Duran for his detailed and stimulating comments on an earlier version of the paper. We also wish to thank (without implicating) R.Boucekkine, D. de la Croix and J.H.Drèze for their thoughtful questions and comments. Financial support from the IAP IV and ARC programmes is gratefully acknowledged.
} 


\begin{abstract}
We construct a stylised intertemporal macroeconomic model to illustrate how the combination of decentralised trading and microeconomic uncertainty can generate coordination problems and indeterminacy of the macroeconomic equilibrium. With a competitive labour market and a fixed labour supply, the range of equilibria depends mainly on the variance of the idiosyncratic shocks and may thus remain fairly narrow . The situation is different when there is imperfect competition on the labour market. The existence of real rigidities is apt to considerably increase the size of the interval of indeterminacy, for a given variance of the shocks.
\end{abstract}

Keywords: indeterminacy, non-Walrasian economy, equilibrium unemployment, coordination, continuum of equilibria

JEL classification: E10, E24 


\section{Introduction}

Business cycle analysts often associate the success or failure of an economic recovery to investors and/or consumers expectations and degree of confidence. Subjective confidence effects can hardly be discussed in standard Walrasian setups wherein the knowledge of the economy's "fundamentals" typically suffices to determine a unique equilibrium trajectory. It is well-known that there is room for "animal spirits" to affect the macroeconomic outcome only if there are market imperfections. This paper focuses on a market imperfection arising from the combination of decentralised trading and microeconomic uncertainty in an intertemporal setup. This combination creates information problems between agents and can make the macroeconomic equilibrium depend on agents' expectations.

In an intertemporal perspective, decentralised trading implies that agents have to make decisions that will commit them on a market (at least temporarily) while they are still uncertain about their future trading opportunities. The simplest example is the choice of a productive capacity under uncertainty about future purchase orders. In a Walrasian setup, such an uncertainty may in the end have little macroeconomic implications, because (it is assumed that) there is ex post full information about each other's trading opportunities. The market works as if there were a centralised market clearing device, which implies that all agents can realise all (ex post) profitable transactions. If however agents do not enjoy such an amount of information, the microeconomic uncertainty may create an information problem between buyers and sellers. A firm may end up ex post with an excess productive capacity if it receives fewer purchase orders than expected, or face a capacity shortage in the opposite case. The possibility of such outcomes affects the firm's investment decision and makes the optimal capital stock depend on expectations about forthcoming orders. In such a non-Walrasian setup, expectations about future trading opportunities may affect the actual level of transactions, and make low activity levels result from low investments following from (self-fulfilling) pessimistic expectations.

Our objective is to formalise these intuitions in a model that departs as little as possible from a standard Walrasian intertemporal macroeconomic model. To introduce the type of information

problem we have in mind, we distinguish final and intermediate goods producers. Intermediate goods producers are all ex ante identical; they use labour and capital to produce an homoge- 
neous good that is the sole input of final goods producers. Both types of firms operate under perfect competition. We consider the case where uncertainty arises from the existence of purely idiosyncratic technological shocks in intermediate firms. These idiosyncratic shocks imply heterogeneous employment and production decisions at the competitive prices and wages. In a Walrasian world, final firms always buy a quantity of intermediate goods such that every intermediate firm is always able to sell its optimal production level. This can occur in a decentralised economy if final firms receive all the relevant information about every intermediate firm's situation and can send purchase orders accordingly. In this case, the microeconomic heterogeneity may have little or no macroeconomic implication. We want to depart slightly from this scenario by analysing the case where final firms send purchase orders to intermediate firms without knowing every intermediate firm's optimal production level. The price of the homogeneous intermediate good fails to convey to buyers the relevant information about every intermediate firm's situation. An intermediate firm enjoying a good productivity shock may then receive too few purchase orders, and vice-versa. The possibility of such outcomes makes the intermediate firms investment choice depend on expected forthcoming purchase orders. It is shown that these expectation effects induce indeterminacy of the macroeconomic equilibrium, even with full employment of a fixed labour supply. This indeterminacy is intrinsically linked to the information problem between buyers and sellers induced by the microeconomic uncertainty. Without idiosyncratic shocks, there is a unique equilibrium, which replicates the Walrasian outcome.

Our paper is related to an already vast literature aiming to understand under what circumstances multiple equilibria can occur in a decentralised economy. Those models have in common the existence of a coordination failure due to some type of "externality" (physical or pecuniary ${ }^{1}$ ). But they differ by the nature of the externality (technological interactions, demand externalities, trading externalities) that is at the root of the coordination problem and generates multiple equilibria. Hart (1982), Heller (1986), Kiyotaki (1988), Roberts (1987, 1989) and others rely on multisectoral models with imperfect competition and "aggregate demand externalities" (in the terminology of Blanchard-Kiyotaki (1987)). Diamond (1982) stresses the effects of decentralised trading in an economy where the Walrasian auctioneer is replaced by a stochastic matching process. Bryant (1983) emphasises imperfect information in a stylised model with complementary

\footnotetext{
${ }^{1}$ For a discussion of these concepts, see Silvestre (1995).
} 
intermediate goods and decentralised decision-making.

Our contribution shares many of the intuitions common to the above-mentioned papers. Our model is different though in that it does not rely on imperfect competition nor on any physical externality or technological complementarity. The model economy only departs from a Walrasian one in the working of a competitive market (the intermediate goods one). This departure would be inconsequential in a world with perfect information. Indeterminacy occurs because the microeconomic uncertainty implies imperfect information between buyers and sellers. There is then a continuum of equilibria that can be indexed by demand expectations. This means that once a relatively pessimistic atmosphere has established itself, a unilateral change in expectations is never profitable. It is only a coordinated change in expectations that can give intermediate firms an incentive to invest more.

We also stress the possible interactions between the mechanism inducing indeterminacy and the presence of real rigidities on the labour market. With a competitive labour market and a fixed labour supply, we show that the range of equilibria depends mainly on the variance of the idiosyncratic shocks. It may thus remain fairly narrow if the variance of these shocks is itself small. The situation becomes totally different when there is imperfect competition on the labour market. Because then both the employment rate and the capital stock change with demand expectations, the existence of real rigidities is apt to considerably increase the size of the interval of indeterminacy, for a given variance of the shocks. This result is in line with Drèze $(1997,1999)$, who emphasises the possibility that, if some relative prices (like the real wage) are downwardly rigid, underutilisation of resources (at prices compatible with fullemployment) may persist once established, reflecting pure coordination failure rather than price distortions.

The rest of the paper is organised as follows. Section 2 is devoted to the description of behaviours and equilibrium conditions in the Walrasian setup used as a benchmark case in the subsequent sections. This framework is adapted in section 3 to the case of a non-Walrasian intermediate goods market. Section 4 introduces imperfect competition on the labour market and assumes that wages are set by a monopoly union. The main conclusions are summarised in section 5 . 


\section{The Walrasian Economy}

We first describe the Walrasian economy that will serve as a benchmark case for the rest of the paper. We consider an economy with two types of firms, final goods producers and intermediate goods producers. Intermediate good producers face a standard neoclassical technological constraint with two inputs (labour and capital), non-increasing returns to scale and idiosyncratic productivity shocks. All intermediate goods are perfect substitutes in the production of a final good. The latter uses no other input. We limit ourselves to the case where the idiosyncratic uncertainty generates no macroeconomic uncertainty, which requires that all firms be ex ante identical. We thus assume perfect foresight of all macro variables.

\subsection{Behaviours}

\section{Intermediate Goods Producers}

We assume a continuum of ex ante identical competitive firms, uniformly distributed over the unit interval. In each firm, total factor productivity is random. With $k_{t}$ units of capital and $\ell_{t}$ units of labour, a firm produces a quantity of output $q_{t}$ given by:

$$
q_{t}=\theta_{t} f\left(k_{t}, \ell_{t}\right)
$$

where $\theta_{t}$ is a stochastic productivity shock, which is firm specific and observed at the beginning of period t. $f$ is concave and strictly increasing $\left(f_{k}, f_{\ell}>0, f_{k k}, f_{\ell \ell}<0\right.$ and $\left.f_{k \ell}>0\right)$; it exhibits non-increasing returns to scale. To further simplify the presentation, we assume that the productivity shock can take only two values (low and high), the same for all firms. More precisely:

$$
\theta_{t}=\left\{\begin{array}{l}
\theta^{-} \quad \text { with probability } \pi \text { satisfying } 0<\pi<1 \\
\theta^{+} \quad \text { with probability } 1-\pi,
\end{array}\right.
$$

and $\theta^{+}>\theta^{-}>0$. Given our assumptions on the distribution of $\theta_{t}, \pi$ represents in every period both the probability that a given firm experiences a low productivity level $\theta^{-}$and the proportion of firms experiencing such a low productivity level. 
Every firm behaves competitively on all markets and thus takes the intermediate goods price $p_{t}$, the wage rate $w_{t}$ and the interest rate $r_{t}$ as given (the final good serves as numéraire).

We assume the following sequence of events and decisions. An investment made in $t-1$ becomes productive in $t$. In period $t-1$, each intermediate goods producer decides on the productive capital stock of the next period $\left(k_{t}\right)$ without knowing the time $t$ value of total factor productivity $\theta_{t}$. The period $t$ employment and production decisions are only taken after the realised value of $\theta_{t}$ has been observed. We analyse this sequence of decisions backwards, starting with employment at given capital stock.

\section{Optimal labour demand}

Given a predetermined capital stock $k_{t}$ and a realised value of the shock, $\theta_{t} \in\left\{\theta^{-}, \theta^{+}\right\}$, the employment decision in period $t$ is the solution of the following programme:

$$
\max _{\ell_{t}} p_{t} \theta_{t} f\left(k_{t}, \ell_{t}\right)-w_{t} \ell_{t}
$$

Let us denote by $\ell_{t}^{-}$and $q_{t}^{-}$(resp. $\ell_{t}^{+}$and $q_{t}^{+}$) the optimal employment and output levels in a firm where productivity is low (resp. high) in period $t$. The optimal employment level $\ell_{t}^{ \pm}$must be such that $\theta^{ \pm} f_{\ell}\left(k_{t}, \ell_{t}^{ \pm}\right)=w_{t} / p_{t}$. This implies:

$$
\ell_{t}^{ \pm}=\ell\left(k_{t}, \omega_{t}, \theta^{ \pm}\right) \quad \text { and } \quad q_{t}^{ \pm}=q\left(k_{t}, \omega_{t}, \theta^{ \pm}\right)
$$

where $\omega_{t}$ is the intermediate firm's real labour cost in period $t$, i.e., $\omega_{t}=w_{t} / p_{t}$. Functions $\ell$ and $q$ are increasing in both $k_{t}$ and $\theta_{t}$ and decreasing in $\omega_{t}$. Appendix 1 derives these functions in the case of a Cobb Douglas technology.

\section{Investment decision}

The individual firm's objective is to maximise the present value of profits discounted at the sure interest rate.

Let $\Pi_{t}^{-}$(resp. $\left.\Pi_{t}^{+}\right)$denote the gross operating profits of a firm experiencing a low (resp. high) productivity shock in $t$. One has

$$
\Pi_{t}^{ \pm}=p_{t} \Pi\left(k_{t}, \omega_{t}, \theta^{ \pm}\right) \quad \text { where } \quad \Pi\left(k_{t}, \omega_{t}, \theta^{ \pm}\right)=q_{t}^{ \pm}-\omega_{t} \ell_{t}^{ \pm} .
$$


Function $\Pi$ is concave in $k_{t}$ and decreasing in $\omega_{t}$.

A firm chooses its investment policy $\left\{k_{t+1}\right\}_{t>0}$ so as to maximise its present value, i.e.,

$$
\max _{\left\{k_{t+1}\right\}_{t \geq 1}} \sum_{t=1}^{\infty} R_{1, t}\left\{\pi \Pi_{t}^{-}+(1-\pi) \Pi_{t}^{+}-\left[k_{t+1}-(1-\delta) k_{t}\right]\right\} .
$$

$k_{1}$ is given, $\delta$ is the depreciation rate (with $0<\delta<1$ ) and $R_{1, t}$ is the discount factor associated to period $t$ : if $r_{s}$ is the real interest rate in period $s, R_{1, t}=\Pi_{s=2}^{t}\left(1+r_{s}\right)^{-1}$ for $t>1$ and $R_{1,1}=1$. The first-order optimality condition of the maximisation of (5) with respect to $k_{t+1}$ is:

$$
\nu_{t+1}=\pi \Pi_{k}\left(k_{t+1}, \omega_{t+1}, \theta^{-}\right)+(1-\pi) \Pi_{k}\left(k_{t+1}, \omega_{t+1}, \theta^{+}\right) \quad \forall t,
$$

where $\nu_{t+1}$ denotes the real capital usage cost $\left(\nu_{t+1}=\left(r_{t+1}+\delta\right) / p_{t+1}\right)$ and $\Pi_{k}$ denotes the first partial derivative of function $\Pi$ with respect to its first argument ${ }^{2}$.

In the case of decreasing returns-to-scale, the first-order optimality condition (6) can be solved for capital:

$$
k_{t+1}=\mathcal{K}\left(\nu_{t+1}, \omega_{t+1}, \Theta\right) \text {, }
$$

where $\Theta$ summarises the parameters characterising the distribution of the idiosyncratic shocks $\left(\Theta=\left(\pi, \theta^{-}, \theta^{+}\right)\right)$. Function $\mathcal{K}$ is decreasing in both $\nu$ and $\omega$. In the case of constant returns to scale, $\Pi_{k}$ does not depend on the level of the capital stock and the optimality condition (6) implies a tight and inverse relationship between capital and labour costs; the optimal size of the individual firm then remains undetermined (see appendix 1 for the Cobb Douglas case).

\section{Final Goods Producers}

To keep the model as simple as possible, we assume that the final good production process uses only intermediate goods. We furthermore assume constant returns to scale ${ }^{3}$ and perfect substitutability between all intermediate goods, that is:

$$
y_{t}=\int_{0}^{1} q_{j t} d j
$$

\footnotetext{
${ }^{2}$ One checks easily that $\Pi_{k}\left(k, \omega, \theta^{ \pm}\right)$is equal to the marginal productivity of capital $\theta^{ \pm} f_{k}\left(k, \ell^{ \pm}\right)$.

${ }^{3}$ Assuming decreasing returns breaks the equality between intermediate and final good prices but does not change our results qualitatively.
} 
where $y_{t}$ is the final output level and $q_{j t}$ is the quantity of input $j$ used in production.

Perfect competition between intermediate good producers implies a unique price $p_{j t}=p_{t}, \forall j$. With the production technology (8), the intermediate goods market clearing condition will further imply that $p_{t}$ be equal to the price of the final good, i.e., $p_{t}=1$.

Whatever its output level, a final firm will make zero profits and will accept to serve any final demand level. Its total demand for intermediate goods is equal to its output level $y_{t}$. In a Walrasian market, the allocation of this total demand across intermediate firms coincides with the Walrasian output levels of those firms.

\section{Consumers}

A representative infinitely-lived consumer supplies inelastically one unit of labour in every period and lends her financial wealth to input firms. Her total revenue coincides with the total gross domestic income: wage and interest rate income, plus the firms' profits. Let $a_{t+1}$ be the real financial wealth of the consumer ${ }^{4}$ at the end of period $t$. Her optimisation programme can then be written as follows:

$$
\begin{aligned}
& \max _{\left\{c_{t}\right\}_{t \geq 1}} \sum_{t=1}^{\infty}\left(\frac{1}{1+\rho}\right)^{t} u\left(c_{t}\right), \\
& \text { subject to: } \quad a_{t+1}+c_{t}=\left(1+r_{t}\right) a_{t}+\Pi_{t}+w_{t}, \quad \forall t \text {, } \\
& \text { and: } \quad \lim _{t \rightarrow \infty} R_{1, t+1} a_{t+1} \geq 0,
\end{aligned}
$$

where $\Pi_{t}$ stands for the total amount of profits distributed by intermediate firms.

The representative consumer's optimal consumption path satisfies the usual first-order condition:

$$
u^{\prime}\left(c_{t}\right)=\frac{1+r_{t+1}}{1+\rho} u^{\prime}\left(c_{t+1}\right), \quad \forall t \geq 1
$$

Alternatively, let $\lambda_{t+1}$ represent the marginal utility of consumption in $t+1$. The optimal consumption behaviour in $t$ is given by

$$
c_{t}=\mathcal{C}\left(\left(1+r_{t+1}\right) \lambda_{t+1}\right),
$$

\footnotetext{
${ }^{4}$ Because there is no aggregate uncertainty, distinguishing shares and loans would add nothing: the equilibrium price of shares will always be such that both types of assets yield the same sure return. With perfect capital markets, adding (lump-sum) taxes and a government sector would introduce no interesting changes. With a fixed amount of government expenditures, it would solely affect the consumption level.
} 
where function $\mathcal{C}\left(\equiv u^{\prime-1}\right)$ is decreasing in its argument.

\subsection{General Equilibrium}

With ex ante identical firms, the equilibrium conditions can be summarised as follows.

On the intermediate goods markets, equilibrium implies that $p_{t}=1$. At given $k_{t}$, all input producers have identical low- or high employment and output levels. I.e., the production level of any intermediate firm is determined by:

$$
q_{t}= \begin{cases}q\left(k_{t}, \omega_{t}, \theta^{-}\right) & \text {if } \theta_{t}=\theta^{-}, \\ q\left(k_{t}, \omega_{t}, \theta^{+}\right) & \text {if } \theta_{t}=\theta^{+} .\end{cases}
$$

The equilibrium condition between the total input demand $\left(y_{t}\right)$ and supply can be written as:

$$
y_{t}=\pi q\left(k_{t}, \omega_{t}, \theta^{-}\right)+(1-\pi) q\left(k_{t}, \omega_{t}, \theta^{+}\right) .
$$

On the final goods market, the equilibrium condition imposes that:

$$
y_{t}=c_{t}+k_{t+1}-(1-\delta) k_{t}
$$

where $c_{t}$ is given by (10) and $k_{t+1}$ is such that (6) is satisfied.

On the labour market, there is full employment of the labour force (normalised to 1). The equilibrium condition is:

$$
1=\pi \ell\left(k_{t}, \omega_{t}, \theta^{-}\right)+(1-\pi) \ell\left(k_{t}, \omega_{t}, \theta^{+}\right)
$$

which, at given initial capital stock $k_{t}$, determines the equilibrium real wage $\omega_{t}$.

Obviously, at given $\lambda_{t+1}$ and $\omega_{t+1}$, the period $t$ equilibrium is uniquely determined ${ }^{5}$. There is also a unique stationary equilibrium, with real interest rate equal to the subjective time discount rate $(r=\rho$, see 9$)$ and thus $\nu=\rho+\delta$.

\footnotetext{
${ }^{5}$ At given capital stock, (14) determines the equilibrium real wage $\omega_{t}$ and therefore the equilibrium output level, $y_{t}$, and the interest rate $r_{t+1}$ (by using (12) and (13) successively).
} 


\section{The non-Walrasian Economy}

With decentralised trading, the Walrasian equilibrium allocation can be reached if and only if every final firm is perfectly and costlessly informed about the optimal production level of every intermediate good supplier. In such a scenario, the fact that there is a microeconomic uncertainty has no deep macroeconomic implication; in particular it does not prevent ex post a perfect match between demands and supplies.

We now turn to the consequences of not assuming perfect information. More specifically, we consider an economy with decentralised trading where final firms have to send purchase orders without full information about the shocks that hit the different input suppliers. An intermediate firm may then face a sales constraint since the orders it receives may fall short of its Walrasian output level. This possibility affects its investment decision and makes the optimal capital stock depend on expectations about forthcoming orders.

We limit ourselves to the case where the final good firm sends the same purchase order $q_{t}^{d}$ to all input firms. This assumption of identical purchase orders is only made for convenience. But it also seems to be a sensible simplification in a setup where the final goods firm cannot distinguish among intermediate goods producers. We further assume that all input firms expect the same purchase orders. This simplification makes all input firms ex ante identical and implies that there will be no macroeconomic uncertainty.

\subsection{Behaviours}

\section{Intermediate Goods Producers}

We analyse backwards a sequence of events and decisions that is, mutatis mutandis, comparable to the one of section 2. At time $t-1$, each firm decides on its capital stock $k_{t}$ without knowing the productivity shock of period $t$, and given its expectations about the future demand for its output $q_{t}^{d}$, the intermediate goods price $p_{t}$ and the wage rate $w_{t}$. The period $t$ employment and production levels are decided later, after the realised value of the productivity shock has been observed. 


\section{Optimal labour demand}

If a firm receives a sufficient quantity of orders, the optimal output and labour demand levels remain determined by (3). If the quantity of orders is smaller than the profitable capacity of the firm, labour demand corresponds to the employment level necessary to produce $q_{t}^{d}$. This employment level $\ell_{t}^{d}$ is such that $\theta f\left(k_{t}, \ell_{t}^{d}\right)=q_{t}^{d}$, i.e.,

$$
\ell_{t}^{d}=\ell^{d}\left(k_{t}, q_{t}^{d}, \theta\right), \quad \theta \in\left\{\theta^{-}, \theta^{+}\right\}
$$

where function $\ell^{d}$ is increasing in $q_{t}^{d}$ and decreasing in the other arguments.

Let $\Pi_{t}^{d}$ be defined as the operating surplus of a sales constrained firm:

$$
\Pi_{t}^{d}=p_{t}\left(q_{t}^{d}-\omega_{t} \ell^{d}\left(k_{t}, q_{t}^{d}, \theta\right)\right)=p_{t} \Pi^{d}\left(k_{t}, q_{t}^{d}, \omega_{t}, \theta\right) .
$$

Function $\Pi^{d}$ is easily shown to be increasing in $q^{d}$ and decreasing in both $k$ and $\omega$.

\section{Optimal capital stock}

We focus on situations where all input firms expect demand to lie in between the low and the high optimal unconstrained output levels. More formally:

$$
q\left(k_{t+1}, \omega_{t+1}, \theta^{-}\right) \leq q_{t+1}^{d} \leq q\left(k_{t+1}, \omega_{t+1}, \theta^{+}\right), \quad \forall t
$$

The optimal capital stock value must obviously satisfy the first inequality, as otherwise firms would be, with probability one, below their Walrasian level of output even in the low productivity state of nature. The second inequality will also be satisfied in our stylised economy because the final firm knows the intermediate goods firm's maximum profitable capacity and has consequently no incentive to send orders larger than this quantity.

Therefore, an intermediate goods firm expects to be sales constrained only in the case where it experiences high productivity level $\theta^{+}$, which occurs with probability $1-\pi$. The capital stock is chosen so as to maximise the following expected present value:

$$
\max _{\left\{k_{t+1}\right\}_{t \geq 1}} \sum_{t} R_{1, t}\left\{\pi \Pi_{t}^{-}+(1-\pi) \Pi_{t}^{d}-\left[k_{t+1}-(1-\delta) k_{t}\right]\right\}
$$

The capital stock $k_{t+1}$ installed at time $t$ is determined by the following first-order optimality condition:

$$
\nu_{t+1}=\pi \Pi_{k}\left(k_{t+1}, \omega_{t+1}, \theta^{-}\right)+(1-\pi) \Pi_{k}^{d}\left(k_{t+1}, q_{t+1}^{d}, \omega_{t+1}, \theta^{+}\right)
$$


where $\Pi_{k}^{d}$ is the first partial derivative of function $\Pi^{d}$ with respect to $k$. The first term on the right-hand side represents the marginal revenue of capital when productivity is low, the second term the marginal revenue of capital when productivity is high. It is through this last term that demand expectations affect the optimal capital stock 6 . More concisely, the above optimality condition determines the optimal capital stock as a function of factor costs and sales expectations:

$$
k_{t+1}=\tilde{\mathcal{K}}\left(\nu_{t+1}, \omega_{t+1}, q_{t+1}^{d}, \Theta\right)
$$

\section{Final Goods Producers}

The objective and the technological constraint of the representative final goods producer remain the same as in section 2. We now assume though that the final goods firm sends the same purchase order $q_{t}^{d}$ to every intermediate goods producer, without knowing which producer has been hit by a low or a high productivity shock. For every intermediate good, there is now a positive probability $\pi$ that the supply will fall short of the ordered quantity and that the firm will only receive $q_{t}^{-}<q_{t}^{d}$. The cost minimisation programme associated to the production of an output level $y_{t}$ can thus be written as follows: ${ }^{7}$ :

$$
\min _{q_{t}^{d}} p_{t}\left[\pi q_{t}^{-}+(1-\pi) q_{t}^{d}\right] \quad \text { subject to: } \quad \pi q_{t}^{-}+(1-\pi) q_{t}^{d}=y_{t},
$$

the solution of which is simply $q_{t}^{d}=\left(y_{t}-\pi q_{t}^{-}\right) /(1-\pi)$. With constant returns-to-scale, final firms make zero profits and their optimal size is not determined (as in the Walrasian economy).

\section{Consumers}

The description of consumers' behaviour remains unchanged.

\footnotetext{
${ }^{6}$ Note that, at given demand expectations, the capital stock remains determinate even in the case with constant returns to scale: in that case, the optimality condition (19) no longer imposes a fixed and tight link between factor costs as in the Walrasian economy. The link between the wage rate and the interest rate now depends on demand expectations. This appears clearly in the Cobb Douglas case proposes in appendix 1.

${ }^{7}$ Under the assumption of perfect substitutability, rationing is inconsequential for a final firm which has correctly anticipated its possibility and suitably modified all input demands.
} 


\subsection{General Equilibrium}

\section{Definition}

In the economy described so far, a full-employment equilibrium in period $t$ is a vector of prices $\left(p_{t}, r_{t+1}, w_{t}\right)$ and a vector of quantities $\left(q_{t}, q_{t}^{d}, y_{t}, k_{t+1}\right)$ such that, at given capital stock $k_{t}$ and given levels of marginal utility of consumption $\lambda_{t+1}$, future demand $\left(q_{t+1}^{d}\right)$ and wage $\left(w_{t+1}\right)$, the following conditions are satisfied:

1. final and intermediate goods producers maximise their expected profits; consumers maximise their utility;

2. on the intermediate goods markets, a proportion $\pi$ of firms experiences a low productivity shock and produces $q_{t}^{-}$, a proportion $1-\pi$ experiences a high productivity shock and produces $q_{t}^{d}$

3. there is competitive equilibrium on all the other markets (labour, capital, final goods).

The set of equilibrium conditions can be written as follows. On the intermediate goods markets, $p_{t}$ is equal to 1 and the equilibrium condition is given by:

$$
y_{t}=\pi q\left(k_{t}, \omega_{t}, \theta^{-}\right)+(1-\pi) q_{t}^{d}
$$

Given the demand for private consumption (see (10)) and the aggregate demand for capital (see (20)), the equilibrium condition on the final good market becomes:

$$
y_{t}=\mathcal{C}\left(\left(1+r_{t+1}\right) \lambda_{t+1}\right)+\tilde{\mathcal{K}}\left(\nu_{t+1}, \omega_{t+1}, q_{t+1}^{d}, \Theta\right)-(1-\delta) k_{t}
$$

Finally, the labour market equilibrium condition implies that labour demand $L\left(k_{t}, \omega_{t}, q_{t}^{d}, \Theta\right)$ be equal to the total workforce (normalised to 1$)$ :

$$
1=L\left(k_{t}, \omega_{t}, q_{t}^{d}, \Theta\right)=\pi \ell\left(k_{t}, \omega_{t}, \theta^{-}\right)+(1-\pi) \ell^{d}\left(k_{t}, q_{t}^{d}, \theta^{+}\right)
$$

Obviously, the equilibrium so defined is not uniquely determined, as the equilibrium conditions (21)-(22)-(23) form a system of three equations in four unknowns. At given initial capital stock 
$k_{t}$ and at given values $\lambda_{t+1}, \omega_{t+1}$ and $q_{t+1}^{d}$, there is a continuum of equilibrium factor prices $\left(w_{t}, r_{t+1}\right)$, activity and demand levels $\left(y_{t}, q_{t}^{d}\right)$. This indeterminacy follows from the assumption that final goods firms send purchase orders without full information about every intermediate goods producer's productivity. This gives a role to demand expectations in the investment decision of those firms.

\section{Interval of indeterminacy at a stationary state}

Let us denote by $z^{*}$ (resp. $\bar{z}$ ) the stationary state value of a variable $z$ in the Walrasian economy (resp. in the non-Walrasian economy). The stationary interest rate is in both cases equal to the consumer's subjective time discount rate: $r^{*}=\bar{r}=\rho$.

At this interest rate, there is a continuum of stationary state equilibria $\left(\bar{w}, \bar{k}, \bar{y}, \bar{q}^{d}\right)$ with full employment in the non-Walrasian economy. To characterise the range of possible steady-state equilibria, we index the equilibrium values of $\bar{w}, \bar{k}, \bar{y}$ by (expected) demand $\bar{q}^{d}$. The extremal values of each variable can be computed by setting demand expectations at their lowest $\left(\bar{q}^{d}=\bar{q}^{-}\right)$ and highest $\left(\bar{q}^{d}=\bar{q}^{+}\right.$) admissible values (see $(17)$ ). We thus define $\bar{k}^{+}$(resp. $\bar{k}^{-}$) as the stationary state capital stock under persistently high (resp. low) demand expectations. We similarly define $\bar{w}^{ \pm}, \bar{y}^{ \pm}$.

By comparing the implications of (20) and (23) (for $\bar{q}^{d}=\bar{q}^{-}$and $\bar{q}^{d}=\bar{q}^{+}$respectively) to those of (7) and (14) in the Walrasian economy, it is easily shown that the non-Walrasian equilibria are bounded from above by the Walrasian equilibrium and that the following ranking holds (see appendix 2 for a discussion of the Cobb-Douglas case):

$$
\bar{k}^{-}<\bar{k}^{+}=k^{*} \quad \text { and } \quad \bar{w}^{-}<\bar{w}^{+}=w^{*} .
$$

A comparable ranking holds for output. The length of the intervals $\left[\bar{k}^{-}, \bar{k}^{+}\right]$and $\left[\bar{w}^{-}, \bar{w}^{+}\right]$cannot be further characterised without more specific assumptions about the production technology. This is done below for the Cobb Douglas case.

The realisation of a particular steady-state equilibrium relies on the fact that demand expectations remain unchanged at some given value within the interval $\left[\bar{q}^{-}, \bar{q}^{+}\right]$. The particular case $\bar{q}^{d}=\bar{q}^{+}$would imply the same transactions as in the Walrasian economy. One might thus wonder why firms' expectations would deviate persistently from $\bar{q}^{+}$along a steady state. In 
our setup, individual rationality does not lead firms to necessarily expect $\bar{q}^{d}=\bar{q}^{+}$. Because an individual firm's decisions have a negligible macroeconomic impact, the individual firm cannot change its own expected sales by its sole action. Being more optimistic and investing more than all the other producers would be suboptimal and lead to a too large capital stock. Being more pessimistic would lead to underinvestment and to loosing profitable sales opportunities. This means that once a relatively pessimistic atmosphere has established itself, a unilateral change in expectations is never profitable. It is only a coordinated change in expectations that can give intermediate firms an incentive to invest more.

The size of the interval of indeterminacy clearly depends on the degree of uncertainty about productivity, i.e. on values $\theta^{+}, \theta^{-}$and the probability $\pi$. It is obvious that the measure of the interval of indeterminacy goes to zero when either $\theta^{+}=\theta^{-}$or when the probability $\pi$ goes to either 1 or 0. I.e., the continuum of equilibria shrinks to the Walrasian equilibrium point when uncertainty vanishes. In the absence of microeconomic uncertainty, the decentralised working of the input market does not raise any information problem and allows the economy to reach the Walrasian optimum.

Note finally that the interval of indeterminacy is necessarily larger at a stationary state than at fixed, predetermined capital stock. In a stationary perspective, persistently high or low demand expectations imply capital stock adjustments. The short-run (negative) output and employment effects of lower demand expectations are thus reinforced in the longer run by downward capital adjustments.

\section{The Cobb Douglas case}

Using the definitions of $\ell_{t}^{-}$and $\ell_{t}^{d}$ (see equations (40) and (44) in appendix 1), aggregate demand for labour can be recast as follows:

$$
\begin{aligned}
L\left(k_{t}, \omega_{t}, q_{t}^{d}, \Theta\right) & =\pi \ell_{t}^{-}+(1-\pi) \ell_{t}^{d} \\
& =\ell_{t}^{-} \vartheta\left(x_{t}\right)
\end{aligned}
$$

where $x_{t} \equiv q_{t}^{d} / q_{t}^{-}$and $\vartheta_{t}$ is defined as

$$
\vartheta\left(x_{t}\right) \equiv \pi+(1-\pi)\left(\frac{\theta^{-}}{\theta^{+}}\right)^{1 / \alpha} x_{t}^{1 / \alpha} .
$$


Variable $x_{t}$ takes values over the interval $\left[1, q_{t}^{+} / q_{t}^{-}\right]$. By using the equations defining $q_{t}^{ \pm}$(see (40)), one easily checks that $\vartheta\left(x_{t}\right)$ takes values over the following interval:

$$
\vartheta^{-} \leq \vartheta\left(x_{t}\right) \leq \vartheta^{+}, \quad \text { where } \quad \vartheta^{ \pm} \equiv\left[\pi+(1-\pi)\left(\frac{\theta^{ \pm}}{\theta^{+}}\right)^{\frac{1}{\alpha}}\left(\frac{\theta^{ \pm}}{\theta^{-}}\right)^{\frac{1}{1-\alpha}}\right] .
$$

At given wage and capital stock, changes in input demand may thus generate changes in the aggregate labour demand within the following interval:

$$
\ell_{t}^{-} \vartheta^{-} \leq L\left(k_{t}, \omega_{t}, q_{t}^{d}, \Theta\right) \leq \ell_{t}^{-} \vartheta^{+}
$$

When demand expectations are persistently high or low, the capital stock adjusts as described by equation (19). One can then show (see appendix 2) that:

$$
\frac{\bar{k}^{-}}{\bar{k}^{+}}=\frac{\bar{\omega}^{-}}{\bar{\omega}^{+}}=\left[\frac{\vartheta^{-}}{\vartheta^{+}}\right]^{\frac{1-\alpha}{1-\beta}} \leq 1,
$$

these ratios going to 1 when uncertainty vanishes.

The long run effects of demand expectations on the aggregate labour demand and on fullemployment equilibrium wages are illustrated in figure 1. The figure is drawn under the assumptions of constant returns to scale and $\pi=0.5, \alpha=1-\beta=2 / 3, \theta^{-} / \theta^{+}=0.98$ and $\theta^{+}=1.1$. With constant returns to scale, the long-run labour demand schedule is a horizontal line defined by (19); its position depends on the capital usage cost and also in our setup on demand expectations $q^{d}$. In the high-expectations case $\left(q^{d}=q^{+}\right)$, all firms are producing at full-capacity as in the standard Walrasian model; the long-run labour demand schedule is represented by the continuous horizontal line. With a vertical labour supply (normalised to 1), the full-employment high-expectations equilibrium coincides with the stationary Walrasian equilibrium. When demand expectations are the most pessimistic $\left(q^{d}=q^{-}\right)$, the labour demand schedule shifts downwards, as shown by the horizontal dotted line. The two downward-sloping curves represent the corresponding short-run labour demand schedules, i.e., they show the effects of wage changes on the aggregate demand for labour at given capital stock, respectively $k^{+}$in the high expectations case (represented by a continuous line) and $k^{-}$in the low expectations case (dashed line). Lower demand expectations imply lower equilibrium wages.

Figure 2 illustrates the effects of demand expectation changes at unchanged capital stock. In this example, the value of the capital stock is fixed at its Walrasian level $\left(k=k^{+}\right)$. When 


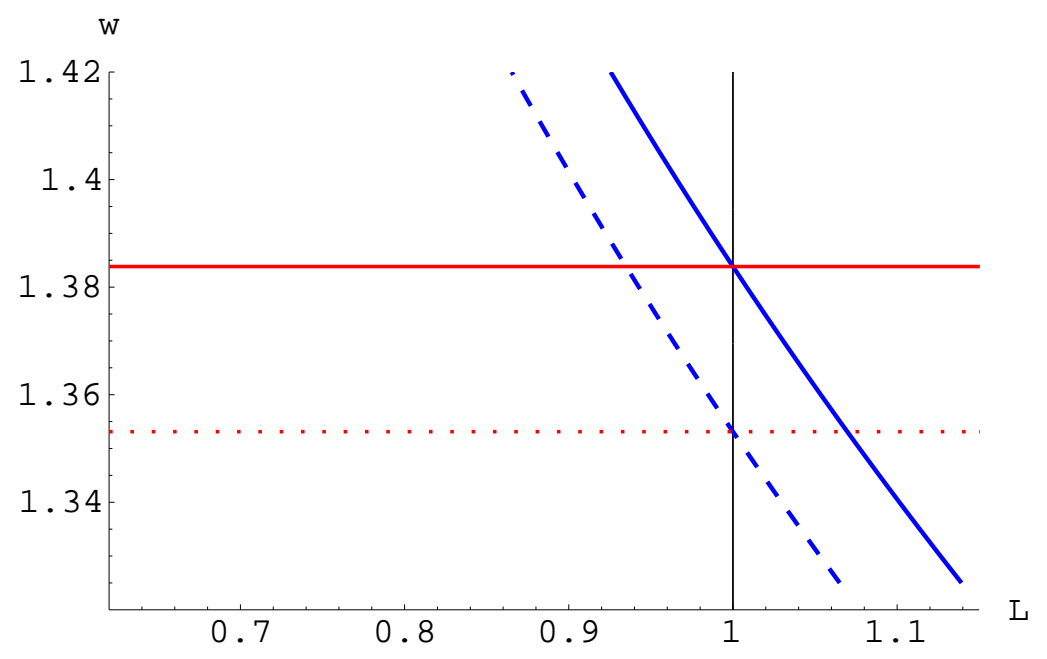

Figure 1: Long-run full-employment equilibria at high- and low demand expectation levels

\begin{tabular}{|l|c|c|}
\hline Parameter values: & & \\
$\alpha=1-\beta=2 / 3, \pi=0.5, \frac{\theta^{-}}{\theta^{+}}=0.98$ & $\frac{w_{\min }}{w_{\max }}$ & $\frac{y_{\min }}{y_{\max }}$ \\
\hline \hline At stationary equilibrium & 0.9774 & 0.9922 \\
\hline At given $k$ & 0.9848 & 0.9998 \\
\hline
\end{tabular}

Table 1: Interval of equilibrium values

demand expectations are high, the short-run aggregate labour demand schedule is given by the continuous downward-sloping curve, as in figure 1. When demand expectations are more pessimistic and take their lowest possible value (given $k$ ), the aggregate demand for labour decreases at all wage levels, as represented by the dashed-dotted line. It is readily seen that the range of full-employment equilibrium wage values is smaller than in the case with capital stock adjustments.

Table 1 provides a numerical illustration of these results. Demand expectations changes have less impact on wages and output in the short run (i.e., at given, predetermined capital stock $k_{t}$ ) than they have in the long run (at the stationary state). Long lasting changes in demand expectations have more effect on equilibrium output than short-lived ones, via their effects on capital accumulation (a kind of accelerator mechanism). 


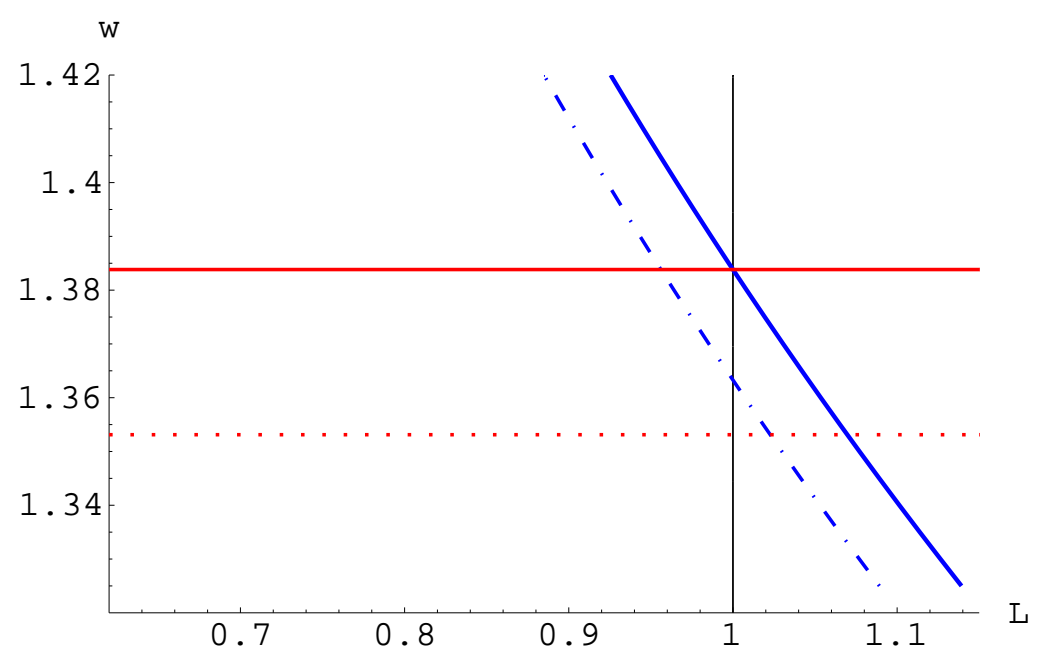

Figure 2: Short-run full-employment equilibria at high- and low demand expectation levels

\section{Unemployment Equilibria}

Up to now we assumed a perfectly competitive labour market with exogenous labour supply. We now introduce real rigidities and show that they may considerably amplify the size of the interval of indeterminacy and of demand expectations effects.

The intuition behind this result is fairly simple. Assume to simplify that firms use constant return technologies. We know that in such circumstances the long run Walrasian labour demand schedule is horizontal, so that the long run (stationary state) equilibrium real wage is entirely determined on the labour demand side. The stationary state value of the capital stock is fixed via the full-employment/fixed labour supply assumption, which determines the size of the economy. Adding idiosyncratic shocks and imperfect information as we did in the previous section enlarges this setup by introducing an interval of stationary equilibrium real wage and capital stock values, as described in (29). The representation of the labour market equilibrium is shown in figure 1. If we now replace the full-employment/fixed labour supply assumption by a fixed real wage assumption, any point in the area delineated by the horizontal continuous and dotted lines (respectively the long-run high- and low-expectations labour demand curves) can be a stationary equilibrium. The size of the economy is no longer determined. As we move towards lower employment rates (to the left in the labour market diagram), it suffices to satisfy the equilibrium conditions that the changes in observed employment be matched by proportional changes in the 
capital stock, and that both the employment and the capital stock changes be proportional to the changes in expected output. For each employment level, demand expectations may of course be high or low (resp. $q^{+}$and $q^{-}$). The ratio between the high- and low-expectation values of the variables remains unchanged. The level of the variables is no longer defined, as each of them (expectations, capital stock and employment level) decreases at the same rate ${ }^{8}$.

This is obviously a too simple and extreme case. A more general representation should take into account the wage adjustments induced by unemployment changes. In order to take such wage adjustments into account, we now consider a simple right-to-manage-monopoly-union model. We assume that the monopoly union behaves myopically and maximises in each period a static objective function with the current employment and real wage rates as arguments. This is admittedly ad hoc, but will suffice to illustrate the effects of real rigidities in the imperfect information setup examined so far. With perfect information, this representation would yield a standard equilibrium unemployment (NAIRU) model, with a unique equilibrium unemployment rate (see for instance Layard etal. (1991)). This representation thus provides a nice benchmark case.

\section{Trade Union Behaviour}

Let function $\mathcal{U}\left(L_{t}, \omega_{t}\right)$ represent the preferences of the monopoly union over employment $L$ and real wage $\omega$ in period $t$. Function $\mathcal{U}$ is increasing and quasi-concave in its arguments.

The union chooses the wage of period $t$ given the labour demand schedule at given capital stock $k_{t}$. Assuming a Cobb Douglas technology (see appendix 1 for details on the behaviour of firms in that case), the union's problem can be represented as follows:

$$
\begin{aligned}
& \max _{\omega_{t}} \mathcal{U}\left(L_{t}, \omega_{t}\right), \\
& \text { subject to } \quad L_{t}=\pi\left(\frac{\alpha \theta^{-}}{\omega_{t}}\right)^{\frac{1}{1-\alpha}} k_{t}^{\frac{\beta}{1-\alpha}}+(1-\pi)\left(\frac{q_{t}^{d}}{\theta^{+}}\right)^{\frac{1}{\alpha}} k_{t}^{-\frac{\beta}{\alpha}} .
\end{aligned}
$$

The optimality condition for $w_{t}$ implies that the wage rate be such that the marginal rate of substitution between wage and employment is equal to (the absolute value of) the wage elasticity

\footnotetext{
${ }^{8}$ This case is an example (admittedly a very specific one) of a Walras-Keynes equilibrium as defined in Drèze (1997).
} 
of employment, that is, the optimal wage rate must satisfy:

$$
\frac{\omega_{t}}{L_{t}} \frac{\mathcal{U}_{\omega}\left(L_{t}, \omega_{t}\right)}{\mathcal{U}_{L}\left(L_{t}, \omega_{t}\right)}=\left|\eta_{t}\right|
$$

where $\eta_{t}$ stands for the wage elasticity of aggregate labour demand. It can be shown to be:

$$
\left|\eta_{t}\right|=\frac{1}{1-\alpha} \frac{\pi \ell_{t}^{-}}{L_{t}}<\frac{1}{1-\alpha}
$$

where $\frac{\pi \ell_{t}^{-}}{L_{t}}$ represents the weighted proportion of firms experiencing a low productivity shock. Because the labour demand of sales-constrained firms is not sensitive to the wage rate, the wage elasticity of aggregate employment is (in absolute value) smaller than in the perfect information case. At given capital stock, it is furthermore decreasing in the aggregate employment level since the weighted proportion of supply-constrained firms then decreases.

By using (25)-(27) in (33), the inverse of $\left|\eta_{t}\right|$ can be written as:

$$
\frac{1}{\left|\eta_{t}\right|}=(1-\alpha) \frac{\vartheta\left(x_{t}\right)}{\pi}, \quad \text { where } \quad 1 \leq x_{t} \leq \frac{q_{t}^{+}}{q_{t}^{-}} \quad \text { and } \quad \vartheta^{-} \leq \vartheta\left(x_{t}\right) \leq \vartheta^{+} \text {. }
$$

The inverse of $\left|\eta_{t}\right|$ thus takes values in the interval:

$$
(1-\alpha) \frac{\vartheta^{-}}{\pi} \leq \frac{1}{\left|\eta_{t}\right|} \leq(1-\alpha) \frac{\vartheta^{+}}{\pi}
$$

The union's optimal wage will thus be larger, ceteris paribus, in situations with larger demand expectations (larger values of $x_{t}$ ), because the aggregate labour demand becomes less sensitive to the wage rate.

\section{Equilibrium Unemployment}

\section{Definition}

An equilibrium with unemployment in period $t$ is a vector of prices $\left\{p_{t}, r_{t+1}, \omega_{t}\right\}$ such that, at given capital stock $k_{t}$ and given expectations on marginal utility of consumption $\lambda_{t+1}$, future demand level $q_{t+1}^{d}$ and future wage $\omega_{t+1}$, the following conditions are satisfied:

1. final and intermediate goods producers maximise expected profits; consumers maximise utility; 
2. on the intermediate goods markets, a proportion $\pi$ of firms experiences a low productivity shock and produces $q_{t}^{-}$, a proportion $1-\pi$ experiences a high productivity shock and produces $q_{t}^{d}$; there is competitive equilibrium on the final good market;

3. on the labour market, the wage rate is set by the union of workers and may imply unemployment.

The equilibrium conditions on the final and intermediate goods market are thus unchanged (see equations (21) and (22)). On the labour market, the equilibrium condition (23) is replaced by:

$$
L\left(k_{t}, \omega_{t}, q_{t}^{d}, \Theta\right)=\pi \ell\left(k_{t}, \omega_{t}, \theta^{-}\right)+(1-\pi) \ell^{d}\left(k_{t}, q_{t}^{d}, \theta^{+}\right) \leq 1
$$

where $\omega_{t}$ is given by (32).

As in the full-employment case, the equilibrium so defined is not uniquely determined. With decentralised trading and microeconomic uncertainty $\left(\theta^{-}<\theta^{+}\right.$and $\left.\pi \in\right] 0,1[)$, the equilibrium unemployment rate is not uniquely defined and depends on demand expectations ${ }^{9}$.

\section{Illustration}

For illustration purposes, let us use the following specific formulation of the union's objective function:

$$
\mathcal{U}\left(L_{t}, \omega_{t}\right)=\left(1+\frac{1}{a L_{t}^{b}}\right)^{-1}\left(1-\frac{\omega_{0}}{\omega_{t}}\right)^{c} \quad \text { with } a>0, \text { and } 0<b, c \leq 1 .
$$

The optimal wage rate is then given by:

$$
\omega_{t}=\left\{1+\frac{c}{b} \frac{1}{\left|\eta_{t}\right|}\left[1+a L_{t}^{b}\right]\right\} \omega_{0}
$$

where $\omega_{0}$ can be interpreted as unemployment benefit. In the particular case where $c=b$ and $a \rightarrow 0$, the wage-setting rule is the one of a utilitarian trade-union with logarithmic preferences. The wage setting-rule would then be a horizontal line in the $\omega-L$ space. Our numerical example is based on the same values as in the previous section for the labour demand function $\left(\pi=0.5, \alpha=1-\beta=2 / 3, \theta^{-} / \theta^{+}=0.98, \theta^{+}=1.10\right)$, and on the following parameter values: $a=0.5, b=1.0, c=0.25, \omega_{0}=1.10$ for the union's objective function. The value of $\omega_{0}$

\footnotetext{
${ }^{9}$ This is consistent with the empirical findings of Lubrano et al. (1996) and Shadman-Sneessens (1998), who find that the equilibrium unemployment rate is not uniquely defined and is affected by both demand- and supply-side variables.
} 
was chosen so as to reproduce the characteristics of the standard Walrasian full-employment equilibrium in the high-expectations case $\left(\bar{q}^{d}=\bar{q}^{+}\right)$.

The locus of stationary unemployment equilibria obtained with these formulations and parameter values is reproduced in figure 3. The two long-run horizontal schedules are the same ones as in figure 1. They represent the long run labour demand behaviours (with capital stock adjustments taken into account) in the two extreme cases with respectively high- and low- demand expectations. The two parallel upward-sloping schedules represent the wage-setting rule (38) in the same two extreme cases. In the low-expectations case (dashed-dotted line), the (absolute value of the) wage elasticity $|\bar{\eta}|$ is higher, and the optimal wage lower. The intersection between the two continuous lines determines the high-expectations stationary equilibrium (with $\bar{x}=\bar{q}^{d} / \bar{q}^{-}=\bar{q}^{+} / \bar{q}^{-}>1$ ). By construction it coincides with the Walrasian equilibrium. The intersection between the dotted horizontal line and the upward-sloping dashed-dotted line determines the low-expectations stationary equilibrium (with $\bar{x}=\bar{q}^{d} / \bar{q}^{-}=1$ ). In this numerical example, the latter entails an equilibrium unemployment rate of about $20 \%$. The two downward-sloping schedules represent the short-run (i.e. at given capital stock) labour demand behaviours. Because the stationary equilibrium value of the capital stock is much lower in the low-expectations case, the corresponding short-run labour demand schedule (the downwardsloping dashed-dotted line) is far on the left of its high-expectations counterpart (the continuous downward-sloping line). All intermediate cases can be similarly obtained, by varying the value $x=q^{d} / q^{-}$. The locus of all stationary unemployment equilibria is represented by the thick dark dashed line of figure 3. Changes in demand expectations generate pro-cyclical real wage changes, and contra-cyclical changes in "equilibrium unemployment".

In the short-run, at fixed predetermined capital stock, (unanticipated) changes in demand expectations cannot have such an enormous impact on equilibrium unemployment. Figure 4 reproduces the same information as figure 3 for the high-expectations case. The low-expectations case is now computed at unchanged capital stock. The change in demand expectations shifts the labour demand schedule to the left, but at unchanged capital stock the shift is limited. The locus of all short-run unemployment equilibria (when the initial capital stock is at a value compatible with full-employment) is represented by the thick dark dashed line of figure 4. It is clear from 


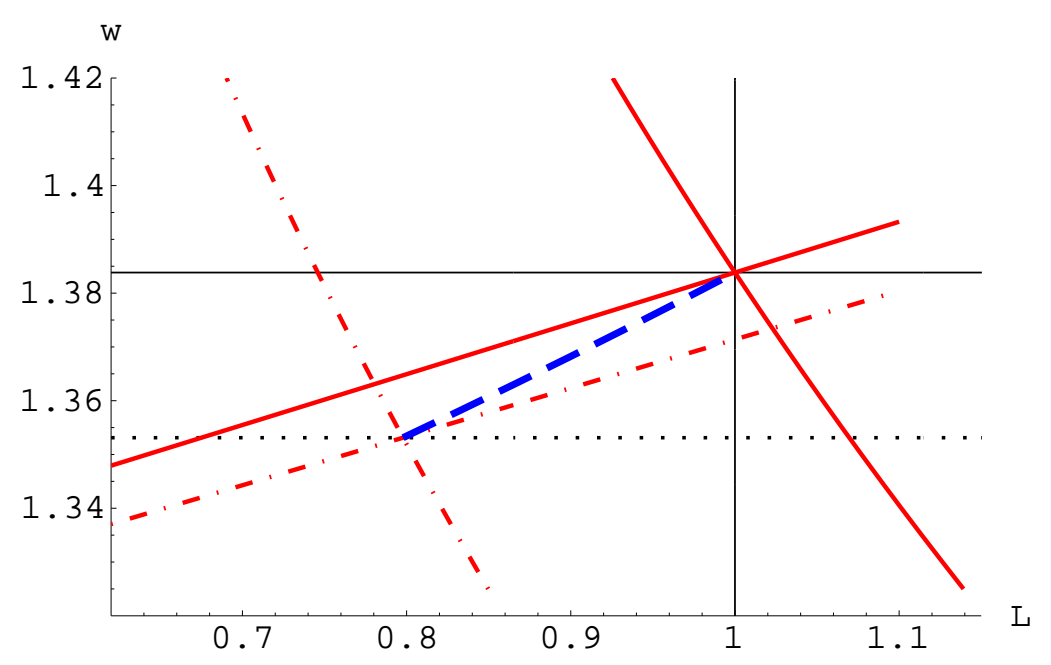

Figure 3: Locus of long-run unemployment equilibria

the comparison of figures 3 and 4 that despite the indetermination, the economy remains fairly stable in the short-run. In the longer-run though, the effects of persistently pessimistic demand expectations are amplified by capital stock adjustments, much more so than in the competitive labour market case.

\section{Conclusions}

This paper illustrates how in a market economy with decentralised trading the existence of a microeconomic uncertainty may create an information problem between agents and generate genuine demand expectations effects (in investment decisions) and equilibrium indeterminacy. It is worth stressing that the range of possible equilibria converges to the unique Walrasian equilibrium in the limit case where the microeconomic uncertainty vanishes: the agents then possess all the relevant information and decentralised trading raises no coordination difficulty. If the labour market is perfectly competitive and there is full-employment of a fixed labour supply, the range of equilibria depends directly on the size of the microeconomic uncertainty. In the presence of real wage rigidities, the size of the indeterminacy may be considerably amplified. At variance with standard equilibrium unemployment models (NAIRU models), there is then a continuum of equilibrium unemployment rates, which can be indexed by demand expectations. Higher demand expectations are associated with higher activity, higher capital stock and wages, 


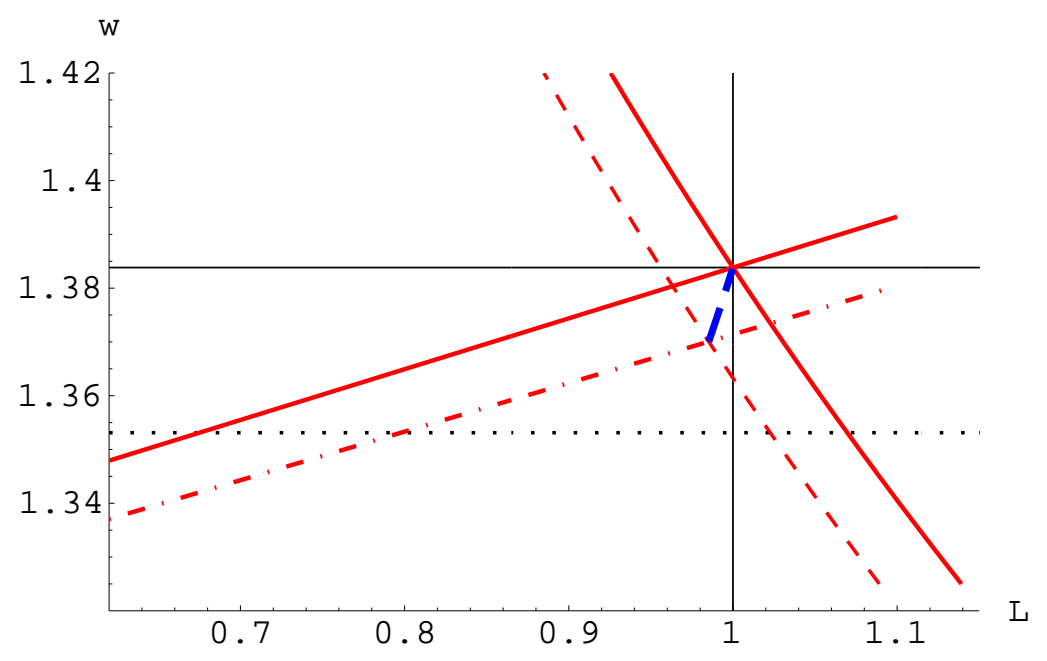

Figure 4: Locus of short-run unemployment equilibria

lower unemployment, and conversely.

The model developed in this paper is admittedly a very stylised one. In an economy like the one sketched here, what each agent needs to anticipate includes the anticipations and behaviours of all the other agents. This aspect should be explored further. Moreover, we have analysed the consequences of a particular form of decentralised trading (sales on order) without justifying it formally. This representation of the working of the intermediate goods market does certainly not provide an adequate description of the working of all goods markets in an actual economy. It stresses though that if on some markets firms produce and sell on orders, there is room for demand expectations effects on the determination of the macroeconomic equilibrium. 


\section{References}

Benhabib J. and R.E.A. Farmer (2000), 3indeterminacy and Sunspots in Macroeconomics", in J.B.Taylor and M.Woodford, Handbook of Macroeconomics, Vol. I A, Amsterdam: NorthHolland

Blanchard-Kiyotaki (1987) "Monopolistic Competition and the Effects of Aggregate Demand" American Economic Review 77(4), 647-666.

Bryant (1983) "A Simple Rational-Expectations Keynes-Type Model", Quartely Journal of Economics, 98, 525-528.

Cooper and John (1988) "Coordinating Coordination Failures in Keynesian Models", Quartely Journal of Economics, 103, 441-463.

Diamond (1982) "Aggregate-Demand Management in Search Equilibrium", Journal of Political Economy,90-5, 881-894.

Drèze J.H. (1997), "Walras-Keynes Equilibria, Coordination and Macroeconomics", European Economic Review, 41:9, 1737-1762.

Drèze J.H. (1999) "On the Macroeconomics of Uncertainty and Incomplete Markets", Presidential Address, 12th World Congress of the International Economic Association, CORE DP 9964, Université catholique de Louvain, Louvain-la-Neuve.

Gali (1996) "Multiple Equilibria in a growth Model with Monopolistic Competition", Economic Theory, 8, 251-266.

Hart O. (1982) “A Model of Imperfect Competition with Keynesian Features", Quartely Journal of Economics, 97, 109-138.

Heller W. (1986) "Coordination Failure under Complete Markets with Applications to Effective Demand", in W.P.Heller, R.M.Starr and D.A.Starrett, eds, Equilibrium Analysis: Essays in Honor of Kenneth J. Arrow, vol 2, Cambridge: Cambridge University Press.

Howitt P. and R.P. McAfee (1992) "Animal Spirits", American Economic Review82(3), 493-507. Jones, L.E. and R.E. Manuelli (1992), "The Coordination Problem and Equilibrium Theories of Recessions" American Economic Review, Vol. 82(3), 451-471.

Kiyotaki(1988) "Multiple Expectational Equilibria under Monopolistic Competition", Quartely Journal of Economics 103(4), 695-713. 
Layard, R., S. Nickell and R. Jackman (1991), Unemployment, Macroeconomic Performance and the Labour Market. Oxford: Oxford University Press.

Lubrano, M., F. Shadman-Mehta and H.R. Sneessens (1996), "Real Wages, Quantity Constraints and Equilibrium Unemployment: Belgium, 1955- 198", Empirical Economics, 21, 427-457.

Roberts, J. (1987), “An Equilibrium Model with Involuntary Unemployment at Flexible, Competitive Prices and Wages", American Economic Review, Vol. 77(5), 856-874.

Roberts, J. (1989), "Involuntary Unemployment and Imperfect Competition: A Game-theoretic Macromodel ", in G.Feiwel, ed., The Economics of Imperfect Competition and Employment: Joan Robinson and Beyond, London: MacMillan.

Shadman-Mehta, F., and H.R. Sneessens (1998), "Demand-Supply Interactions and Unemployment Dynamics : Can there be Path Dependency? The case of Belgium, 1955-1994", IRES DP9817, Department of Economics, Université catholique de Louvain, Louvain-la-Neuve.

Silvestre J. (1995) "Market Power in Macroeconomic Models: New Developments", Annales d'économie et de statistique, 37/38, 319-356. 


\section{Appendix 1: Firms' behaviour with Cobb Douglas technologies}

Assume the following Cobb Douglas technology

$$
q_{t}=\theta_{t} \ell_{t}^{\alpha} k_{t}^{\beta}, \quad \alpha+\beta \leq 1,
$$

\section{The Walrasian economy}

The employment and production decisions are

$$
\ell_{t}^{ \pm}=\ell\left(k_{t}, \omega_{t}, \theta^{ \pm}\right)=\left[\frac{\alpha \theta^{ \pm}}{\omega_{t}} k_{t}^{\beta}\right]^{\frac{1}{1-\alpha}} \quad \text { and } \quad q_{t}^{ \pm}=q\left(k_{t}, \omega_{t}, \theta^{ \pm}\right)=\theta^{ \pm}\left[\frac{\alpha \theta^{ \pm}}{\omega_{t}} k_{t}^{\beta / \alpha}\right]^{\frac{\alpha}{1-\alpha}}
$$

$\Pi_{t}^{-}\left(\operatorname{resp} . \Pi_{t}^{+}\right)$then becomes

$$
\Pi_{t}^{ \pm}=(1-\alpha) p_{t} q\left(k_{t}, \omega_{t}, \theta^{ \pm}\right)
$$

The optimality conditions on $k_{t+1}$ writes as follows

$$
\frac{r_{t+1}+\delta}{p_{t+1}}=\beta\left[\pi \theta^{-}\left(\frac{\alpha \theta^{-}}{\omega_{t+1}}\right)^{\frac{\alpha}{1-\alpha}}+(1-\pi) \theta^{+}\left(\frac{\alpha \theta^{+}}{\omega_{t+1}}\right)^{\frac{\alpha}{1-\alpha}}\right]\left(k_{t+1}\right)^{-\frac{1-\alpha-\beta}{1-\alpha}}, \quad \forall t .
$$

Therefore,

$$
k_{t+1}=\left[\frac{\beta}{\nu_{t+1}}\right]^{\frac{1-\alpha}{1-\alpha-\beta}}\left[\pi \theta^{-}\left(\frac{\alpha \theta^{-}}{\omega_{t+1}}\right)^{\frac{\alpha}{1-\alpha}}+(1-\pi) \theta^{+}\left(\frac{\alpha \theta^{+}}{\omega_{t+1}}\right)^{\frac{\alpha}{1-\alpha}}\right]^{\frac{1-\alpha}{1-\alpha-\beta}}, \quad \forall t .
$$

By using the optimality condition (43), one checks easily that the expected value of profits is given by:

$$
(1-\alpha-\beta) p_{t}\left[\left(\frac{\alpha}{\omega_{t}}\right)^{\alpha}\left(\frac{\beta}{\nu_{t}}\right)^{\beta}\left[\mathrm{E}(\tilde{\theta})^{\frac{1}{1-\alpha}}\right]^{1-\alpha}\right]^{\frac{1}{1-\alpha-\beta}} \geq 0, \forall t .
$$

Expected profits are nil in the constant returns-to-scale case, positive otherwise.

\section{The non-Walrasian economy}

$$
\ell_{t}^{d}=\ell^{d}\left(k_{t}, q_{t}^{d}, \theta^{+}\right)=\left[\frac{q_{t}^{d}}{\theta^{+}}\right]^{1 / \alpha}\left(k_{t}\right)^{-\beta / \alpha} \leq \ell_{t}^{+} .
$$

In $t$, a firm installs a capital stock level $k_{t+1}$ given by the following first-order optimality condition:

$$
\nu_{t+1}=\frac{\beta}{\alpha} \omega_{t+1}\left[\pi\left(\frac{\alpha \theta^{-}}{\omega_{t+1}}\right)^{1 / 1-\alpha}\left(k_{t+1}\right)^{\frac{\alpha+\beta-1}{1-\alpha}}+(1-\pi)\left(\frac{q_{t+1}^{d}}{\theta^{+}}\right)^{1 / \alpha}\left(k_{t+1}\right)^{-\frac{\alpha+\beta}{\alpha}}\right]
$$




\section{Appendix 2: Stationary equilibria with full employment}

\section{The general case}

In a stationary equilibrium of the Walrasian economy, the investment equation (6) and the labour market clearing condition (14) become

$$
\begin{aligned}
\rho+\delta & =\pi \pi_{k}\left(k, \omega, \theta^{-}\right)+(1-\pi) \pi_{k}\left(k, \omega, \theta^{+}\right) \\
1 & =\pi \ell\left(k, \omega, \theta^{-}\right)+(1-\pi) \ell\left(k, \omega, \theta^{+}\right)
\end{aligned}
$$

and determine the stationary values $\left(k^{*}, \omega^{*}\right)$.

In a stationary equilibrium of the non-Walrasian economy, the investment equation (19) and the labour market clearing condition (23) become

$$
\begin{aligned}
\rho+\delta & =\pi \pi_{k}\left(k, \omega, \theta^{-}\right)+(1-\pi) \pi_{k}^{d}\left(k, q^{d}, \omega, \theta^{+}\right) \\
1 & =\pi \ell\left(k, \omega, \theta^{-}\right)+(1-\pi) \ell^{d}\left(k, q^{d}, \theta^{+}\right)
\end{aligned}
$$

and determine the stationary values $(\bar{k}, \bar{\omega})$ in function of $\bar{q}^{d}$.

Let $\bar{\omega}^{-}$and $\bar{k}^{-}$(resp. $\bar{\omega}^{+}$and $\bar{k}^{+}$) represent the real wage and capital stock level in a stationary equilibrium where firms have persistently low (resp. high) demand expectations, i.e. where $\bar{q}^{d}=\bar{q}^{-}\left(\operatorname{resp} . \bar{q}^{d}=\bar{q}^{+}\right)$.

Substituting $q^{d}$ by $q^{-}$and $q^{+}$respectively into (48-49) makes obvious that $\bar{k}^{-}<\bar{k}^{+}$and $\bar{\omega}^{-}<$ $\bar{\omega}^{+}$.

Furthermore, when $q^{d}=q^{+}=q\left(k, \omega, \theta^{+}\right)$, (49) is obviously identical to (47) because

$$
\ell^{d}\left(k, q^{d}=q^{+}, \theta^{+}\right)=\ell\left(k, \omega, \theta^{+}\right)=\ell^{+} .
$$

Similarly, (48) is identical to (46) when $q^{d}=q^{+}$: indeed,

$$
\begin{aligned}
\left.\pi_{k}^{d}\left(k, q^{d}, \theta^{+}\right)\right|_{q^{d}=q^{+}} & =-\left.\omega \frac{\mathrm{d} \ell^{d}\left(k, q^{d}, \theta^{+}\right)}{\mathrm{d} k}\right|_{q^{d}=q^{+}} \\
& =-\left.\omega \frac{f_{k}\left(k, \ell^{d}\right)}{f_{\ell}\left(k, \ell^{d}\right)}\right|_{\ell^{d}=\ell^{+}} \text {since } \omega=\theta^{+} f_{\ell}\left(k, \ell^{+}\right) \\
& =\theta^{+} f_{k}\left(k, \ell^{+}\right) \quad \\
& =\pi_{k}\left(k, \omega, \theta^{+}\right) .
\end{aligned}
$$


Consequently, (48-49) is identical to (46-47) when $q^{d}=q^{+}$and thus admits the same solution: i.e., $\left(\bar{k}^{+}, \bar{\omega}^{+}\right)=\left(k^{*}, \omega^{*}\right)$.

\section{The Cobb Douglas case}

Let us first focus on the stationary state equilibrium of the Walrasian economy. The labour market clearing condition (14) gives the following relationship between the equilibrium real wage and the installed capital stock

$$
\omega_{t}=\alpha \theta^{-} k_{t}^{\beta}\left(\pi+(1-\pi)\left(\frac{\theta^{+}}{\theta^{-}}\right)^{1 /(1-\alpha)}\right)^{1-\alpha}
$$

From (43), one has

$$
k^{*}=\left(\frac{\beta}{\nu} \frac{\omega^{*}}{\alpha}\right)^{\frac{1-\alpha}{1-\alpha-\beta}}\left(\frac{\alpha \theta^{-}}{\omega^{*}}\right)^{\frac{1}{1-\alpha-\beta}}\left(\pi+(1-\pi)\left(\frac{\theta^{ \pm}}{\theta^{-}}\right)^{1 /(1-\alpha)}\right)^{\frac{1-\alpha}{1-\alpha-\beta}} .
$$

Substituting $\omega^{*}$ by its value from (50) into the demand for capital (51) gives the following stationary capital stock level:

$$
k^{*}=\left(\frac{\beta}{\nu}\right)^{\frac{1}{1-\beta}}\left(\pi+(1-\pi)\left(\frac{\theta^{+}}{\theta^{-}}\right)^{1 /(1-\alpha)}\right)^{\frac{1-\alpha}{1-\beta}} .
$$

In a stationary equilibrium of the non-Walrasian economy, (14) implies that when firms have persistently low (resp. high) demand expectations one has

$$
\bar{w}^{ \pm}=\alpha \theta^{-}\left(\bar{k}^{ \pm}\right)^{\beta}\left(\pi+(1-\pi)\left(\frac{\theta^{ \pm}}{\theta^{+}}\right)^{1 / \alpha}\left(\frac{\theta^{ \pm}}{\theta^{-}}\right)^{1 /(1-\alpha)}\right)^{1-\alpha} .
$$

Similarly from (45),

$$
\bar{k}^{ \pm}=\left(\frac{\beta}{\nu} \frac{\bar{\omega}^{ \pm}}{\alpha}\right)^{\frac{1-\alpha}{1-\alpha-\beta}}\left(\frac{\alpha \theta^{-}}{\bar{\omega}^{ \pm}}\right)^{\frac{1}{1-\alpha-\beta}}\left(\pi+(1-\pi)\left(\frac{\theta^{ \pm}}{\theta^{+}}\right)^{1 / \alpha}\left(\frac{\theta^{ \pm}}{\theta^{-}}\right)^{1 /(1-\alpha)}\right)^{\frac{1-\alpha}{1-\alpha-\beta}}
$$

Introducing (53) into the capital labour demand (54) then gives

$$
\bar{k}^{ \pm}=\left(\frac{\beta}{\nu}\right)^{\frac{1}{1-\beta}}\left(\pi+(1-\pi)\left(\frac{\theta^{ \pm}}{\theta^{+}}\right)^{1 / \alpha}\left(\frac{\theta^{ \pm}}{\theta^{-}}\right)^{1 /(1-\alpha)}\right)^{\frac{1-\alpha}{1-\beta}} .
$$

A comparison between (52) and (55) makes obvious that $\bar{k}^{-}<\bar{k}^{+}=k^{*}$. Furthermore, dividing (54) for $\bar{k}^{+}$by (54) for $\bar{k}^{-}$gives the value of the ratio $\bar{k}^{+} / \bar{k}^{-}$given in the main text. After introducing (55) into (53), one obtains easily the same value for the ratio $\bar{w}^{+} / \bar{w}^{-}$. 